\title{
Análise da expansão por umidade e absorção de água de pisos cerâmicos comerciais em relação à composição química e à quantidade estimada de fase vítrea
} (Analysis of moisture expansion and water absorption of commercial ceramic
tiles in relation with chemical composition and estimated glassy phase content)

\author{
R. R. Menezes $^{1}$, A. M. Segadães ${ }^{2}$, H. S. Ferreira ${ }^{1}$, H. C. Ferreira ${ }^{1}$ \\ ${ }^{1}$ Departamento de Engenharia de Materiais, CCT, UFPB \\ Av. Aprígio Veloso, 882, Bodocongó, Campina Grande, PB, 58109-970. \\ ${ }^{2}$ Departamento de Engenharia Cerâmica e do Vidro, Universidade de Aveiro, Portugal \\ segadaes@cv.ua.pt,heber@dema.ufpb.br
}

\begin{abstract}
Resumo
Expansão por umidade (EPU) é o aumento das dimensões do corpo cerâmico devido à adsorção de água, podendo ter grande influência na vida útil dos materiais cerâmicos. Este trabalho tem por objetivo relacionar a EPU e a absorção de água de pisos cerâmicos comerciais, com a sua composição química e a quantidade estimada de fase vítrea, calculada utilizando-se o diagrama de equilíbrio de fases do sistema $\mathrm{SiO}_{2} \cdot \mathrm{Al}_{2} \mathrm{O}_{3} \cdot \mathrm{K}_{2} \mathrm{O}$ e a regra da alavanca. Foram estudadas amostras de vinte e três tipos de pisos cerâmicos comerciais. Foi realizada a análise química das amostras (via úmida) e determinada a sua EPU e absorção de água (ensaios realizados de acordo com a norma Brasileira NBR 13818). Foi também determinada a área superficial específica de algumas amostras por adsorção de nitrogênio (BET). Os resultados obtidos mostram genericamente uma proporcionalidade inversa entre a EPU e a absorção de água, para a maioria das amostras, e a análise utilizando o diagrama de fases sugere uma relação decrescente entre a absorção de água e a quantidade estimada de fase vítrea, e uma relação crescente entre a EPU e a quantidade estimada de fase vítrea.

Palavras-chave: EPU, diagramas de fases, absorção de água.
\end{abstract}

Abstract

\begin{abstract}
Moisture expansion is the size increase of the ceramic body due to water adsorption and can have a great influence in the ceramic material service life. This work aims to relate the moisture expansion and water absorption of commercial ceramic tiles with their chemical composition and estimated glassy phase content, calculated from the phase equilibrium diagram of the system $\mathrm{SiO} \cdot \mathrm{Al} \mathrm{O}_{3} \cdot \mathrm{K}_{2} \mathrm{O}$ using the lever rule. Samples of twenty three commercial ceramic tiles were studied. The chemical composition of the samples was obtained (wet route) and their moisture expansion and water absorption were determined (according to the Brazilian standard NBR 13818). The specific surface area of some samples was also determined, using the nitrogen adsorption methodology (BET). The results obtained generally show an inverse proportionality between the moisture expansion and the water absorption, for the majority of the samples. The analysis using the phase diagram suggests an inverse proportionality between the water absorption and the estimated glassy phase content and a direct proportionality between the moisture expansion and the quantity of glassy phase.

Keywords: moisture expansion, phase diagrams, water absorption.
\end{abstract}

\section{INTRODUÇ̃̃O}

Expansão por umidade (EPU) é o termo geralmente utilizado para designar o aumento das dimensões dos materiais cerâmicos, notadamente tijolos, telhas e revestimentos cerâmicos, ocasionado pela adsorção de água. Essa expansão geralmente ocorre lentamente e é relativamente pequena mas, mesmo assim, pode comprometer a aderência das placas cerâmicas ao contrapiso, levar ao gretamento do vidrado [1] e conduzir ao aparecimento de trincas em tijolos [2], caso as tensões geradas pela deformação contida das peças excedam a resistência limite dos materiais.

Junto com o ataque de sais, a EPU é a causa mais comum de deterioração de tijolos, telhas e placas cerâmicas de revestimento, em todo o mundo, tendo atraído a atenção de cientistas desde o final dos anos 20, notadamente na África do Sul, Austrália, certos países da Europa e Estados Unidos [3].

No período entre 1926 e 1950 vários artigos foram publicados sobre este assunto, mas sua preocupação centravase principalmente no gretamento de vidrados [4]. Mesmo com alguns artigos dedicando-se aos danos da EPU em edificações, apenas por volta de 1954 essa questão ganhou 
uma maior evidência, através dos relatos de McBurney [5]. Os estudos sobre EPU foram intensificados após a segunda guerra mundial, principalmente na Inglaterra e Austrália, onde foi observada uma série de colapsos nas alvenarias e estruturas de edificações, que mais tarde foram atribuídas à EPU.

A partir de metade da década de cinqüenta passou-se a estudar com mais profundidade a influência da composição mineralógica e microestrutural na EPU dos corpos cerâmicos, destacando-se os trabalhos de Smith [6], Milne [7] e Young e Brownell [8]. Em particular, Smith [6] mostrou que, devido à atração intermolecular, a superfície de um sólido possui a característica que para os líquidos é chamada tensão superficial, e isto é responsável por uma compressão do interior do sólido; se a água, ou outro líquido, é adsorvido à superfície, esta adsorção irá reduzir a energia superficial do sólido e conseqüentemente aliviar a compressão dentro do sólido. E quando esta tensão é reduzida, o sólido comportase elasticamente e expande. Verificou-se ainda [6] que as fases amorfas são as mais reativas com a umidade e, por conseguinte, mais susceptíveis de provocarem elevada EPU no corpo cerâmico, enquanto que as fases vítreas e cristalinas são, nesta ordem, menos reativas com a umidade. Seguindo essa linha de pesquisa, foi evidenciada a influência do teor de álcalis, das razões de óxidos (especificamente alumina/ sílica e álcalis/sílica) e da composição mineralógica na EPU dos corpos cerâmicos.

Mesmo sendo a cinética e a extensão do fenômeno de EPU muito dependente da composição mineralógica das matérias primas que compõem a massa cerâmica, deve-se ter em mente que há uma estreita relação entre a composição do corpo e a temperatura e o tempo de queima, no que se refere aos seus efeitos sobre a EPU. De fato, se a composição cerâmica não for submetida a um tempo suficiente de maturação e a uma correta temperatura de queima, as reações, previstas pelo equilíbrio, não irão se completar e o corpo resultante estará propenso a conter uma porosidade elevada, grande quantidade de fases vítreas e/ou amorfas e fases residuais reativas com a água [3].

Neste sentido, o trabalho de Yetka e Alizadeh [9] ilustra com bastante clareza o efeito combinado da composição química e do ciclo de queima na EPU, por mostrar que peças com elevada porosidade apresentaram EPU menor que peças com baixa porosidade, pois continham fases cristalinas resultantes da presença de aditivos na massa cerâmica. Observou-se assim que, dependendo da sua constituição mineralógica, mesmo corpos propensos à penetração de elevada quantidade de água podem se apresentar resistentes a EPU.

Dificultando ainda mais qualquer tipo de correlação, também se verifica que a porosidade e a superfície específica de corpos cerâmicos, quando sob ação da água, não permanecem constantes com o tempo. Um dos possíveis motivos dessas variações com o tempo é a corrosão da fase vítrea pela água, aumentando a sua energia superficial e abrindo poros antes fechados [10]. O aumento contínuo da EPU ao longo do tempo, que não pode ser explicado apenas em termos de atividade superficial [11], também pode ser explicado por esse aumento da quantidade exposta da fase vítrea na estrutura, causado pela água.

Assim, alguns pesquisadores [12] consideram que a porosidade e a absorção de água, não são indicadores muito sensíveis da EPU de corpos cerâmicos, ressaltando que não há necessariamente uma relação de proporcionalidade direta entre EPU e porosidade. Entretanto alguns outros autores $[13,14]$ mostraram que a expansão (determinada por autoclavagem) e o ganho de peso por absorção de água estão relacionadas de uma forma que, ainda que não linear, dependente da temperatura de queima e da composição do corpo cerâmico.

Milne [7] observou haver uma correlação linear entre a EPU (determinada por autoclavagem) e a absorção de água, enquanto que Young e Brownell [8] verificaram que a correlação entre a EPU (determinada por autoclavagem) e a absorção só era realmente linear para temperaturas de queima superiores à temperatura de "EPU máxima" (correspondente à liberação de compostos amorfos altamente reativos, que provocam picos de expansão quando se analisa a EPU em função da temperatura de queima). As observações de Young e Brownell [8] foram confirmadas por Cole [15], que observou que para temperaturas de queima superiores à temperatura de "EPU máxima", havia uma correlação de proporcionalidade direta, enquanto que para temperaturas inferiores, a relação era linear, todavia de proporcionalidade inversa. Estas observações foram ratificadas posteriormente por Boucher [16].

O efeito combinado de fase vítrea e composição mineralógica foi bem evidenciado por Vaughan e Dinsdale [17], que mostraram a variação da área específica e da EPU (determinada por autoclavagem) com o aumento da temperatura de queima. Estes autores verificaram que ocorria uma redução da superfície específica com o aumento da temperatura, devido a vitrificação do corpo, ao passo que a EPU inicialmente se elevava e em seguida decrescia com o aumento da temperatura. O aumento inicial da EPU foi atribuído a modificações da composição mineralógica que resultaram em fases potencialmente mais expansivas, enquanto que o decréscimo posterior foi atribuído à diminuição da superfície específica (proporcionada pelo aumento de fase vítrea).

No entanto, deve ser ressaltado que uma diminuição de superfície específica em virtude de uma maior vitrificação do corpo, não deve ser necessariamente encarada como fator redutor da EPU, já que o efeito de corrosão da fase vítrea (cuja severidade depende muito do tipo de ensaio utilizado para determinar a EPU), pode vir a ser um fator predominante.

Assim, observa-se que a EPU está relacionada com a porosidade do material, as fases formadas durante a queima e suas quantidades após arrefecimento. Sendo conhecidas as particularidades de queima dos corpos e suas composições químicas, podem utilizar-se os diagramas de fases, apesar de se referirem a relações de equilíbrio, para obter informações que facilitam a interpretação e entendimento dos fenômenos que ocorrem durante a queima de corpos cerâmicos e para se 
ter uma melhor visão do comportamento da EPU em função da composição química e do tipo de fases formadas.

Os principais constituintes dos corpos cerâmicos "tradicionais" são a alumina e a sílica e, entre os constituintes minoritários, os óxidos de ferro e os alcalinos são responsáveis pela formação de fase líquida a baixas temperaturas (agentes fundentes durante a queima). Os óxidos de ferro formam, com a alumina e a sílica, sistemas ternários onde a fusão se inicia a temperatura de $1200{ }^{\circ} \mathrm{C}$ ou acima; com os alcalinos, o início de fusão ocorre em torno de 1000 ${ }^{\circ} \mathrm{C}$ ou abaixo; quando em conjunto, os óxidos de ferro reforçam a ação fundente dos alcalinos, fazendo com que a fusão se inicie a temperaturas ainda mais baixas e com fase líquida mais abundante. Os alcalinos mais comuns, que são os óxidos de potássio e de sódio, originam líquidos viscosos, com dificuldade em cristalizar, que tendem a permanecer no corpo queimado como fases vítreas. Como os diagramas de fases dos sistemas sílica-alumina-alcalinos são morfologicamente muito semelhantes, e o óxido de potássio é o que conduz a temperaturas de fusão inicial mais baixas, o sistema $\mathrm{SiO}_{2}$ $\mathrm{Al}_{2} \mathrm{O}_{3}-\mathrm{K}_{2} \mathrm{O}$ pode ser usado como modelo na interpretação deste fenômeno [3].

Este trabalho tem por objetivo relacionar a EPU e absorção de água de pisos cerâmicos comerciais com a sua composição química e a quantidade de fase vítrea, estimada utilizando-se o diagrama de equilíbrio de fases do sistema $\mathrm{SiO}_{2}-\mathrm{Al}_{2} \mathrm{O}_{3}-\mathrm{K}_{2} \mathrm{O}$ (S-A-K).

\section{MATERIAIS E MÉTODOS}

\section{Materiais}

Foram estudadas vinte três amostras comerciais de placas cerâmicas para revestimentos, adquiridas no comércio da cidade de Campina Grande - PB, oriundas de estados do sudeste e nordeste. As placas utilizadas, em sua grande maioria materiais de base vermelha e fabricadas pelo processo de queima rápida, possuíam as dimensões de $20 \times 20 \mathrm{~cm}^{2}$ e $30 \times 20 \mathrm{~cm}^{2}$. A temperatura máxima atingida durante o fabrico é desconhecida e apenas alguns fabricantes indicam o grupo de absorção de água dos materiais, nas suas embalagens. Mais informações sobre as amostras estudadas, como suas referências e fabricantes, podem ser encontrada em Menezes [18].

\section{Metodologia}

A composição química das várias amostras foi obtida por análise via úmida $\left(\mathrm{SiO}_{2}, \mathrm{Al}_{2} \mathrm{O}_{3}, \mathrm{Fe}_{2} \mathrm{O}_{3}, \mathrm{CaO}, \mathrm{MgO}, \mathrm{Na}_{2} \mathrm{O}\right.$ e $\mathrm{K}_{2} \mathrm{O}$, perda ao fogo e resíduo insolúvel), segundo métodos do Laboratório de Análises Minerais do CCT/PRAI/UFPB.

A determinação de absorção de água foi realizada segundo a metodologia descrita no anexo B da norma NBR 13818 (foi utilizado um número de corpos de prova maior do que o indicado na norma, a fim se de obter uma maior precisão nos resultados). Com o intuito de comparação com o ensaio de EPU, também foi determinada a absorção após $24 \mathrm{~h}$ de fervura (a norma prescreve fervura por $2 \mathrm{~h}$ ).

A quantidade de fase vítrea presente nas amostras foi estimada utilizando-se o diagrama de fases do sistema $\mathrm{SiO}_{2}-\mathrm{Al}_{2} \mathrm{O}_{3}-\mathrm{K}_{2} \mathrm{O}$. Como as amostras foram produzidas por ciclos de queima rápida (habitualmente tempos de queimas em torno de 30 min e temperaturas máximas entre 1100 e $1200^{\circ} \mathrm{C}$ ), partiu-se das hipóteses simplificadoras de que a queima atingiu a temperatura de $1100{ }^{\circ} \mathrm{C}$ e que, em virtude do rápido resfriamento das amostras, toda a fase líquida formada na queima permaneceria nas amostras como fase vítrea.

Assim, utilizou-se o diagrama de equilíbrio de fases do sistema $\mathrm{SiO}_{2}-\mathrm{Al}_{2} \mathrm{O}_{3}-\mathrm{K}_{2} \mathrm{O}$ e a regra da alavanca planar, após reduzir as composições químicas das amostras à base ternária $\mathrm{SiO}_{2}-\mathrm{Al}_{2} \mathrm{O}_{3}-\left(\mathrm{K}_{2} \mathrm{O}+\mathrm{Na}_{2} \mathrm{O}\right)$, para calcular a quantidade de fase líquida em equilíbrio a $1100{ }^{\circ} \mathrm{C}$. $\mathrm{O}$ valor obtido foi tomado como estimativa da quantidade de fase vítrea presente.

A determinação da EPU seguiu a metodologia definida no anexo J da NBR 13818. Durante a execução do ensaio de determinação da EPU foi adotada a seguinte nomenclatura para as EPUs: a obtida após a requeima inicial e que indica a expansão já sofrida pelo corpo cerâmico desde sua fabricação até o momento do ensaio, foi designada por EPU "atual"; a expansão determinada após fervura e que tem por fim prever a expansão limite do material, foi designada por EPU "potencial".

A EPU foi determinada através de dilatometria (dilatômetro BP Engenharia modelo RB3000). As amostras, já expandidas em ensaio de fervura de acordo com a norma, foram submetidas a requeima com taxa de aquecimento de $150^{\circ} \mathrm{C} / \mathrm{h}$, patamar de $2 \mathrm{~h}$ a $550^{\circ} \mathrm{C}$ e resfriamento natural, sendo a expansão (EPU "potencial") dada pela variação dimensional (linear) registrada pelo dilatômetro.

Foram realizadas duas determinações, sendo a EPU expressa pela média dessas determinações; todavia, quando as medições diferiram em um valor superior a $0,05 \mathrm{~mm} / \mathrm{m}$ foi efetuada uma nova determinação. Os corpos de prova para determinação da EPU tiveram dimensões de aproximadamente $0,7 \times 0,7 \times 5,0 \mathrm{~cm}^{3}$, sendo retirados do centro das placas cerâmicas.

A superfície específica de dez amostras, escolhidas aleatoriamente, foi determinada pelo método de adsorção de $\mathrm{N}_{2}$ usando He como gás de arraste (BET), sendo utilizado um equipamento Micromeritics, Gemini 2370 v5.00.

\section{RESULTADOS E DISCUSSÃO}

\section{Análise Química}

A Tabela I apresenta os resultados da análise química das placas estudadas (ordenadas por teores crescentes de óxidos alcalinos, para facilidade de discussão posterior). Pode-se observar que as amostras continham teores elevados de sílica, variando de $59,59 \%$ a $69,09 \%$, e quantidades de alumina entre $15,02 \%$ e 22,90\%, com predominância de valores acima de $19 \%$. As amostras com base branca apresentaram teores de óxido de ferro variando de $1,75 \%$ a $3,35 \%$ enquanto que, para as de base vermelha, esses teores variaram entre $4,31 \%$ e $9,18 \%$.

A Tabela I mostra também que os teores de óxidos de sódio e potássio situaram-se entre $0,7 \%$ e $3,5 \%$ o que, juntamente 
com as quantidades de óxido de ferro, perfaz um total de óxidos fundentes variando de $3,9 \%$ a $5,8 \%$, no caso das placas com base branca, e de $6,5 \%$ a $11,2 \%$ no caso das placas com base vermelha.

Encontram-se na literatura várias tentativas de relacionar a EPU com a composição química dos corpos cerâmicos, sendo a mais conhecida a proposta por Young e Brownell [8], que sugerem uma dependência linear crescente entre a EPU e a razão $\left(\mathrm{K}_{2} \mathrm{O}+\mathrm{Na}_{2} \mathrm{O}\right) / \mathrm{Al}_{2} \mathrm{O}_{3}$ e outra decrescente com a razão $\mathrm{Al}_{2} \mathrm{O}_{3} / \mathrm{SiO}_{2}$. Assim, a fim de se analisarem as possíveis correlações entre a EPU e a composição química, à semelhança do observado na literatura, foram calculadas as razões $A / S$, $(\mathrm{K}+\mathrm{N}) / \mathrm{A}$ e $\mathrm{K} / \mathrm{A}$. Observou-se que as razões $\mathrm{A} / \mathrm{S}$ e $(\mathrm{K}+\mathrm{N}) / \mathrm{A}$ variaram de 0,25 a 0,38 e de 0,03 a 0,19 respectivamente e que razão K/A situou-se entre 0,02 e 0,12 .

\section{Absorção de Água}

A Tabela II apresenta os resultados obtidos, segundo a norma NBR 13818, para a absorção de água das placas estudadas. Pode-se observar que os valores variaram de 2,24 a $12,42 \%$ aproximadamente, abrangendo os grupos de absorção Ib, IIa e IIb. Apenas duas amostras, Sant'Ana e Terragrés, se situaram, respectivamente, nas faixas de absorção entre 0,5 e 3,0\% (grupo Ib) e 3,0 e 6,0\% (grupo IIa).

Com o intuito de possibilitar uma análise comparativa entre

Tabela I - Composição química das placas cerâmicas estudadas.

[Table I - Chemical composition of the studied ceramic tiles.]

\begin{tabular}{|c|c|c|c|c|c|c|c|c|c|c|}
\hline \multirow[t]{2}{*}{ Amostras } & \multicolumn{10}{|c|}{ Composição Química (\% peso) } \\
\hline & $\mathbf{P R}^{b}$ & $\mathrm{SiO}_{2}$ & $\mathrm{Al}_{2} \mathrm{O}_{3}$ & $\mathrm{Fe}_{2} \mathrm{O}_{3}$ & $\mathrm{CaO}$ & MgO & $\mathrm{Na}_{2} \mathrm{O}$ & $\mathrm{K}_{2} \mathrm{O}$ & $\mathbf{R I}^{b}$ & Total \\
\hline Porto Velho A & 0,35 & 59,67 & 22,39 & 7,66 & $*$ & * & 0,13 & 0,54 & 8,50 & 99,24 \\
\hline Cordeiro & 0,28 & 64,35 & 22,90 & 5,85 & * & $*$ & 0,20 & 0,54 & 5,64 & 99,76 \\
\hline Elizabeth C & 0,44 & 65,66 & 20,41 & 6,07 & $*$ & $*$ & 0,41 & 0,47 & 6,00 & 99,46 \\
\hline Porto Velho C & 0,65 & 61,02 & 20,12 & 7,67 & $*$ & $*$ & 0,13 & 1,54 & 8,67 & 99,80 \\
\hline Escurial A & 0,31 & 61,66 & 19,94 & 7,74 & 2,24 & 2,40 & 0,33 & 1,45 & 2,70 & 98,77 \\
\hline Escurial C & 0,93 & 61,80 & 22,13 & 7,98 & * & $*$ & 0,26 & 1,75 & 4,71 & 99,56 \\
\hline Santa Maria A & 0,78 & 60,20 & 15,02 & 8,38 & $*$ & $*$ & 1,38 & 1,33 & 12,45 & 99,54 \\
\hline Ferreira & 2,02 & 68,34 & 18,68 & 6,07 & $*$ & $*$ & 1,14 & 1,04 & 2,28 & 99,57 \\
\hline Santa Maria C & 0,49 & 59,59 & 16,67 & 9,18 & $*$ & * & 1,09 & 1,01 & 11,59 & 99,62 \\
\hline Porto Rico & 0,43 & 68,10 & 19,08 & 4,47 & 1,96 & 2,6 & 1,14 & 1,30 & 0,82 & 99,90 \\
\hline Sta. Gertrudes & 1,12 & 66,29 & 21,60 & 6,1 & $*$ & $*$ & 0,53 & 1,94 & 2,22 & 99,80 \\
\hline Terragres $^{a}$ & 0,62 & 69,00 & 19,07 & 3,35 & $*$ & $*$ & 0,41 & 2,06 & 5,34 & 99,85 \\
\hline Eliane $^{a}$ & 0,97 & 67,60 & 21,83 & 2,63 & $*$ & $*$ & 1,42 & 1,44 & 3,90 & 99,79 \\
\hline Topazzio & 1,01 & 64,13 & 20,85 & 6,90 & * & 2,00 & 0,33 & 2,48 & 2,26 & 99,96 \\
\hline Elizabeth A & 0,28 & 66,44 & 19,70 & 6,19 & $*$ & $*$ & 1,43 & 1,51 & 4,39 & 99,94 \\
\hline Tatuí & 0,90 & 67,57 & 20,66 & 5,19 & $*$ & $*$ & 0,95 & 2,15 & 2,44 & 99,86 \\
\hline Samarsa & 0,42 & 65,08 & 19,91 & 4,79 & 2,24 & 2,40 & 1,00 & 1,99 & 1,74 & 99,57 \\
\hline Incefra & 0,64 & 69,09 & 20,41 & 5,09 & $*$ & $*$ & 1,80 & 1,40 & 1,32 & 99,75 \\
\hline Sant'Ana $^{a}$ & 0,64 & 65,60 & 24,30 & 1,75 & * & $*$ & 0,13 & 2,06 & 5,28 & 99,76 \\
\hline ICF & 1,20 & 68,84 & 18,27 & 4,31 & $*$ & * & 2,10 & 1,35 & 3,78 & 99,85 \\
\hline Incopisos & 0,64 & 64,94 & 19,64 & 5,99 & $*$ & * & 1,35 & 2,08 & 4,66 & 99,30 \\
\hline SmaltColor & 0,91 & 67,47 & 19,26 & 4,79 & $*$ & $*$ & 1,48 & 2,11 & 3,70 & 99,72 \\
\hline Incesa & 1,04 & 63,14 & 19,50 & 6,95 & $*$ & 2 & 1,69 & 1,94 & 3,56 & 99,82 \\
\hline
\end{tabular}

a Placas de base branca; ${ }^{b}$ PR - Perda ao Rubro; RI-Resíduo Insolúvel; * Traços 
Tabela II - Valores de absorção de água, superfície específica (BET), fase vítrea (estimada a partir do diagrama de fases) e expansão por umidade "atual" e "potencial" das placas cerâmicas estudadas.

[Table II - Water absorption, specific surface area (BET), glassy phase content (estimated from the phase diagram) and moisture expansion of the studied ceramic tiles.]

\begin{tabular}{|c|c|c|c|c|c|c|c|}
\hline \multirow[b]{2}{*}{ Amostras } & \multicolumn{2}{|c|}{ Absorção de água (\%) } & \multirow{2}{*}{$\begin{array}{c}\text { BET } \\
\left(\mathrm{m}^{2} / \mathrm{g}\right)\end{array}$} & \multirow{2}{*}{$\begin{array}{l}\left(\mathrm{K}_{2} \mathrm{O}+\mathrm{Na}_{2} \mathrm{O}\right) \\
\text { corrigido }(\%)\end{array}$} & \multirow{2}{*}{$\begin{array}{c}\text { Fase Vítrea } \\
\text { estimada (\%) }\end{array}$} & \multicolumn{2}{|c|}{ EPU (\%) } \\
\hline & $(2 \mathrm{~h})$ & $(24 \mathrm{~h})$ & & & & atual & potencial \\
\hline Porto Velho A & $10,11 \pm 1,36$ & 9,77 & 0,2985 & 0,81 & 8,33 & 0,030 & 0,033 \\
\hline Cordeiro & $11,60 \pm 0,63$ & 12,99 & 0,3018 & 0,84 & 8,93 & 0,013 & 0,015 \\
\hline Elizabeth C (IIb*) & $8,90 \pm 0,29$ & 9,44 & - & 1,01 & 10,20 & 0,009 & 0,004 \\
\hline Porto Velho C & $9,23 \pm 1,45$ & 9,33 & - & 2,02 & 22,41 & 0,027 & 0,031 \\
\hline Escurial A & $10,81 \pm 0,80$ & 12,76 & - & 2,13 & 24,14 & 0,011 & 0,018 \\
\hline Escurial C & $11,50 \pm 0,76$ & 10,64 & 0,1855 & 2,34 & 25,37 & 0,019 & 0,012 \\
\hline Sant'Ana & $2,24 \pm 0,56$ & 3,44 & - & 2,38 & 26,39 & 0,011 & 0,007 \\
\hline Ferreira (III*) & $8,17 \pm 0,91$ & 8,32 & - & 2,44 & 26,53 & 0,044 & 0,045 \\
\hline Santa Maria C & $9,71 \pm 0,72$ & 9,87 & - & 2,68 & 28,57 & 0,006 & 0,006 \\
\hline Porto Rico & $6,37 \pm 0,55$ & 6,68 & 0,0268 & 2,72 & 30,00 & 0,013 & 0,007 \\
\hline Santa Gertrudes & $8,61 \pm 1,37$ & 8,73 & 0,9419 & 2,73 & 30,01 & 0,032 & 0,043 \\
\hline Terragrés $\left(5-7 \% \%^{\#}\right)$ & $5,27 \pm 0,18$ & 5,90 & 0,1902 & 2,73 & 30,01 & 0,010 & 0,011 \\
\hline Eliane $(\mathrm{IIb} *)$ & $6,42 \pm 0,30$ & 7,11 & - & 3,10 & 30,65 & 0,004 & 0,013 \\
\hline Topazzio & $7,37 \pm 1,12$ & 8,72 & - & 3,20 & 31,25 & 0,095 & 0,096 \\
\hline Elizabeth A (IIb*) & $8,82 \pm 0,19$ & 9,39 & - & 3,30 & 34,48 & 0,010 & 0,010 \\
\hline Tatuí (IIb*) & $7,87 \pm 1,01$ & 8,30 & 0,6069 & 3,39 & 35,48 & 0,046 & 0,047 \\
\hline Samarsa & $12,42 \pm 0,56$ & 13,13 & 0,2189 & 3,40 & 35,63 & 0,012 & 0,012 \\
\hline Incefra $\left(\mathrm{IIb}^{*}\right)$ & $7,83 \pm 0,50$ & 7,06 & 0,3205 & 3,45 & 36,21 & 0,029 & 0,040 \\
\hline Santa Maria A & $9,25 \pm 0,64$ & 9,92 & - & 3,48 & 36,96 & 0,011 & 0,008 \\
\hline ICF (IIb*) & $9,85 \pm 0,61$ & 9,38 & 0,2799 & 3,81 & 38,46 & 0,014 & 0,011 \\
\hline Incopisos (IIb*) & $8,54 \pm 1,27$ & 8,86 & - & 3,90 & 40,63 & 0,023 & 0,022 \\
\hline Smalt Color & $8,79 \pm 0,91$ & 9,22 & - & 3,97 & 41,38 & 0,013 & 0,017 \\
\hline Incesa $\left(\mathrm{IIb}^{*}\right)$ & $6,01 \pm 0,58$ & 6,81 & - & 4,21 & 45,83 & 0,015 & 0,014 \\
\hline
\end{tabular}

* Grupo de absorção de água indicado pelo fabricante (IIb refere-se a absorção de 6-10\% e III a absorção >10\%)

* Referência usada pelo fabricante para indicar a absorção de água

os valores de absorção de água, quantidade de fase vítrea estimada e a EPU, também foi determinada a absorção após 24 h de fervura, já que é esta a metodologia do ensaio de determinação da EPU. Os valores obtidos para a absorção de água após $24 \mathrm{~h}$ estão também indicados na Tabela II.

Com base na Tabela II pode-se concluir que os valores obtidos para a absorção de água após $24 \mathrm{~h}$ de fervura são muito semelhantes aos obtidos após fervura por $2 \mathrm{~h}$. Lembrando que na determinação da absorção após $2 \mathrm{~h}$ de fervura foi usado um número bem maior de corpos de prova do que na fervura por
$24 \mathrm{~h}$ (que, neste caso, nem sequer permitiu o cálculo do desvio padrão), e dada a semelhança entre os valores obtidos nos dois tipos de ensaio, foi considerado que os valores obtidos após fervura por $2 \mathrm{~h}$ deverão ser os utilizados na análise posterior com relação a EPU e a quantidade estimada de fase vítrea.

\section{Estimativa da Quantidade de Fase Vitrea}

Todos os materiais estudados (Tabela I) são constituídos majoritariamente por $\mathrm{SiO}_{2}$ e $\mathrm{Al}_{2} \mathrm{O}_{3}$, tendo como fundentes o 


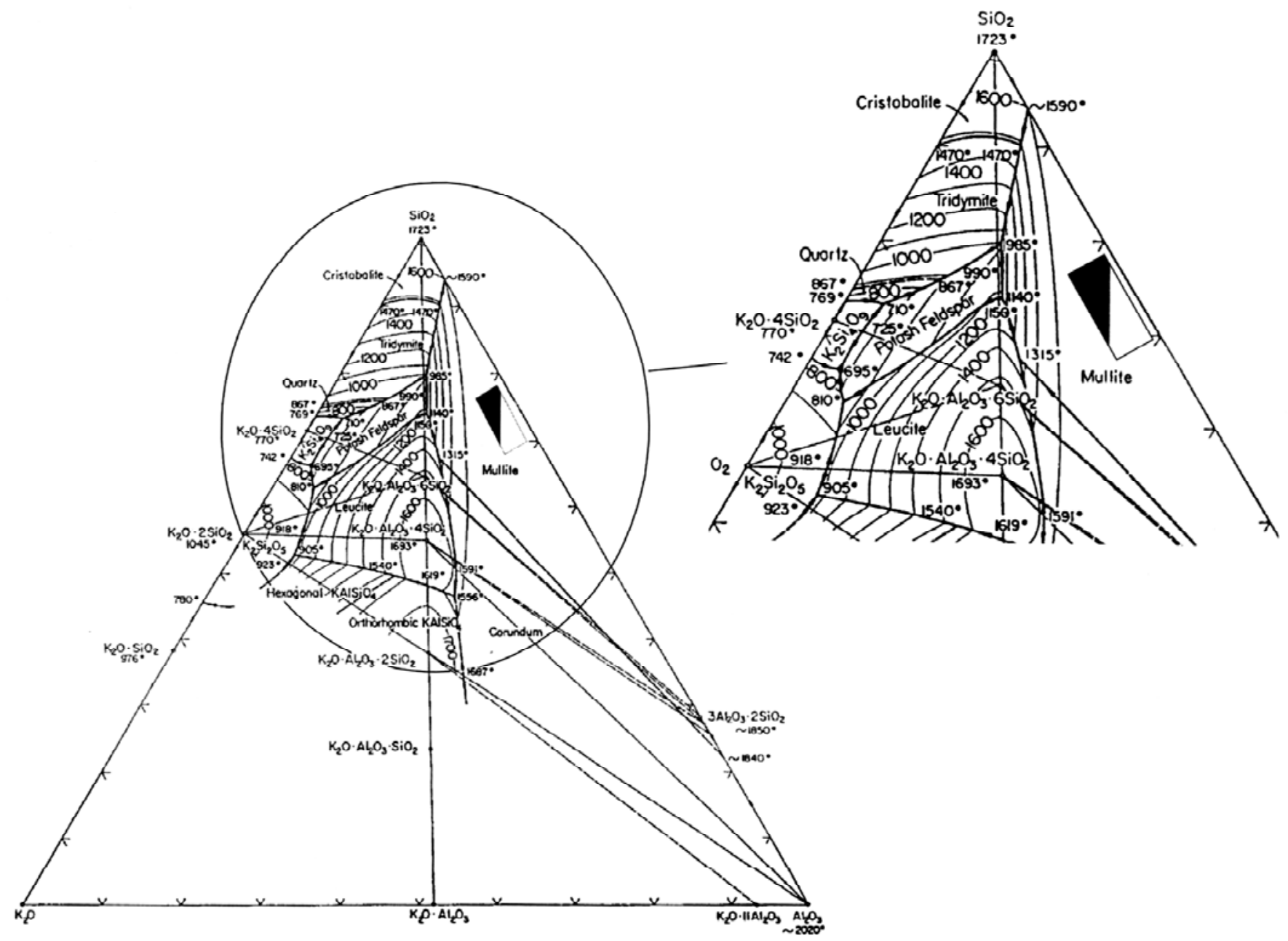

Figura 1: Diagrama de fases do sistema $\mathrm{SiO}_{2}-\mathrm{Al}_{2} \mathrm{O}_{3}-\mathrm{K}_{2} \mathrm{O}$ e localização geral das composições.

[Figure 1: Phase diagram of the $\mathrm{SiO}_{2}-\mathrm{Al}_{2} \mathrm{O}_{3}-\mathrm{K}_{2} \mathrm{O}$ system and general location of the compositions.]

$\mathrm{Fe}_{2} \mathrm{O}_{3}, \mathrm{Na}_{2} \mathrm{O}$ e $\mathrm{K}_{2} \mathrm{O}$. Como já referido, a presença do óxido de ferro, seja na sua forma reduzida, seja na oxidada, irá reforçar o efeito fundente dos óxidos alcalinos, fazendo com que o sistema modelo que melhor se adequa à análise das composições em termos de diagramas de fases, seja o sistema $\mathrm{SiO}_{2}-\mathrm{Al}_{2} \mathrm{O}_{3}-\mathrm{K}_{2} \mathrm{O}$, considerando o teor de óxido de potássio como sendo o total de alcalinos $\left(\mathrm{K}_{2} \mathrm{O}+\mathrm{Na}_{2} \mathrm{O}\right)$ [3]. Para utilizar o diagrama de fases deste sistema, reproduzido na Fig. 1, é necessário recalcular primeiro as composições das placas em termos de apenas $\mathrm{SiO}_{2}+\mathrm{Al}_{2} \mathrm{O}_{3}+\left(\mathrm{K}_{2} \mathrm{O}+\mathrm{Na}_{2} \mathrm{O}\right)$. Todas as composições corrigidas ficam localizadas (Fig. 1) no sub-sistema sílica-mulita-feldspato, onde o início de fusão ocorre a $985^{\circ} \mathrm{C}$. Nas composições reais, a presença dos demais óxidos fará com que se forme fase líquida a temperatura inferior a esta.

A segunda simplificação introduzida é considerar que todas as placas foram queimadas a uma mesma temperatura, que se escolheu ser $1100^{\circ} \mathrm{C}$, para não superestimar a quantidade de fase vítrea (os revestimentos cerâmicos são em geral queimados entre 1100 e $1200^{\circ} \mathrm{C} \mathrm{em}$ ciclos em torno de 30 minutos). A quantidade de fase líquida teoricamente presente nas composições em equilíbrio a $1100{ }^{\circ} \mathrm{C}$ foi considerada como estimativa da quantidade de fase vítrea que permanece nas placas após queima.
A Tabela II apresenta os resultados obtidos desta forma.

Analisando a localização das composições no diagrama de fases, verifica-se que todas estão relacionadas pelo mesmo triângulo conjugado durante a formação e desenvolvimento da fase líquida (triângulo sílica-mulita-líquido). Tal como referido na literatura [3], neste triângulo a quantidade de fase líquida é determinada exclusivamente pelo teor de óxidos alcalinos, qualquer que seja o valor da razão alumina/sílica na composição. A Tabela II mostra que teores crescentes de óxidos alcalinos geram quantidades crescentes de fase líquida a $1100^{\circ} \mathrm{C}$ (fase vítrea). No entanto, o efeito desta fase líquida formada durante a queima será condicionado pelo processamento prévio das placas (granulometria e condições de conformação) e não terá necessariamente uma relação equivalente durante a densificação do corpo (porosidade final e absorção de água).

Com base na absorção de água (por $2 \mathrm{~h}$ ) e na quantidade estimada de fase vítrea (Tabela II) foi construída a Fig. 2, que ilustra o comportamento da absorção de água das amostras em relação à quantidade estimada de fase vítrea (foi observado um comportamento semelhante quando as estimativas de fase vítrea são obtidas com base apenas nos teores de $\mathrm{K}_{2} \mathrm{O}$ ). 




Figura 2: Quantidade estimada de fase vítrea versus a absorção de água. [Figure 2: Estimated glassy phase content versus water absorption.]

Através da Fig. 2 observa-se uma tendência geral de decréscimo da absorção de água com o aumento da quantidade de fase vítrea, o que se faz evidente pelas seqüências 1, 2 e 3 ilustradas no gráfico. Esse comportamento é justificado pelo fato de que o aumento da fase vítrea provoca uma diminuição na porosidade do material e, por conseguinte da acessibilidade da água e sua absorção. A existência de uma série de pontos que não se agrupam em determinada seqüência, deve-se às características e peculiaridades de cada material e à possibilidade de que a fase vítrea presente em algumas amostras não esteja necessariamente preenchendo os poros do material, sendo uma fase vítrea incipiente, que não atua diminuindo efetivamente a absorção de água.

As seqüências ilustradas na Fig. 2 não têm por fim indicar a existência de modelos matemáticos que exprimam relações entre absorção de água e teor de fase vítrea, já que o interrelacionamento desses parâmetros é dependente de uma série de fatores, tais como, composição das matérias primas, características de queima, tipos de poros presentes no material e cinética de difusão. Assim as seqüências devem ser entendidas como "indicadoras" de uma relação inversamente proporcional entre absorção e quantidade de fase vítrea, para uma larga variedade de amostras.

\section{Expansão por Umidade (EPU)}

A Tabela II também apresenta os valores obtidos para as expansões "atual" e "potencial". Com base na Tabela II observa-se que os valores da EPU "atual" e "potencial" variaram entre 0,004 e $0,095 \%$ e 0,004 e $0,096 \%$ respectivamente, havendo grande concentração de dados entre 0,010 e $0,040 \%$, tanto na expansão "atual" como na "potencial". Verifica-se também que apenas a amostra "Topazzio" apresentou valor de EPU "potencial" $(0,096 \%)$ superior ao limite recomendado pela NBR 13818 (0,06\%).
Pode-se observar que algumas amostras apresentaram valores de EPU "potencial" (i.e. após fervura) iguais ou mesmo ligeiramente inferiores aos valores de EPU "atual", o que sugere que o ensaio de fervura não impõe às peças condições muito severas de expansão. Se, por um lado, este fato confirma que o ensaio de fervura não conduz a valores não realistas, o que é uma crítica frequente ao ensaio de autoclavagem, também revela certa inadequação do método de determinação da expansão "potencial", pois poderá subestimar a expansão futura do corpo durante sua vida útil, mesmo considerando o comportamento logarítmico da EPU com o tempo.

\section{EPU e Composição Química}

Como mencionado anteriormente, encontram-se na literatura várias relações entre a EPU e a composição química dos corpos cerâmicos, sendo as mais conhecidas as propostas por Young e Brownell [8]. Assim, foram investigadas possíveis relações entre a EPU e a composição química das amostras, tanto em termos das tradicionais razões alumina/ sílica e óxidos alcalinos/alumina, como com os óxidos alcalinos e alcalinos terrosos isolados e as quantidades totais de fundentes. Os gráficos obtidos não revelaram correlações



Figura 3: Absorção de água versus EPU “potencial”.

[Figure 3: Water absorption versus moisture expansion.]

óbvias entre a EPU e a composição química, havendo grande dispersão dos resultados. Apesar de as amostras apresentarem composições químicas bastante semelhantes, as características peculiares de processamento de cada uma, que não são conhecidas, conduzirão a microestruturas distintas que podem condicionar, ou até mesmo contrariar, o efeito esperado a partir da composição química.

\section{EPU e Absorção de Água}

Com os valores de EPU "potencial" e os valores de 
absorção de água após $2 \mathrm{~h}$ de fervura (Tabela II), foi construída a Fig. 3. A Fig. 3 mostra que se podem agrupar as amostras em quatro grupos, dois deles apresentando relação decrescente entre a absorção e a EPU e os outros dois evidenciando uma relação crescente. As tendências apresentadas na Fig. 3 estão de acordo com resultados descritos na literatura, principalmente os referidos por Cole [13] e Boucher [14]. Este comportamento pode ser explicado, para uma dada composição, pelas curvas de EPU em função da temperatura de queima, e melhor ainda se nessas curvas houver indicação quanto ao desenvolvimento da porosidade (ou área específica) dos corpos em função da temperatura de queima, tal como apresentado por Vaughan e Dinsdale [17].

De forma geral pode-se dizer que as curvas presentes na Fig. 3 ilustram dois tipos de comportamento. As seqüências 1 e 2 (decrescentes) provavelmente relacionam materiais cuja queima não atingiu a maturação ótima: quando a queima é insuficiente (em temperatura ou tempo), o material apresentase altamente poroso (o que implica alta absorção), mas não contém fases amorfas (que conduzem a elevadas EPUs); com o desenvolvimento da queima, há rearranjos na estrutura, a formação de fases amorfas (resultantes de decomposições de fases presentes no corpo cerâmico) e o início da formação de fase líquida, o que pode contribuir para a diminuição da porosidade (e da absorção), mas também pode promover um aumento gradual da EPU, já que as fases cristalinas são as menos susceptíveis à EPU, e atinge-se, eventualmente, um máximo de EPU.

As seqüências 3 e 4 (crescentes) relacionarão materiais que atingiram, ou se aproximaram, da maturação: com a consolidação progressiva do corpo cerâmico, tende a haver uma diminuição simultânea da EPU e da porosidade do material, essencialmente por dois motivos: as fases amorfas



Figura 4: Quantidade estimada de fase vítrea versus a EPU "potencial".

[Figure 4: Estimated quantity of glassy phase versus moisture expansion.] formadas anteriormente tendem a reagir transformando-se em cristalinas e/ou vítreas; e há o aumento da quantidade de fase líquida no material, que passa a ter um efeito mais significativo na diminuição da porosidade do material (e conseqüentemente na sua absorção de água), proporcionando uma menor acessibilidade a água e, por fim, menor EPU.

Assim pode-se inferir que as amostras que compõem as seqüências 1 e 2 são materiais que não apresentam uma estrutura bem consolidada, sendo provavelmente formadas por grande quantidade de fases vítreas e amorfas. Enquanto que as seqüências 3 e 4 provavelmente se referem a amostras com estruturas bem mais consolidadas, comparativamente as demais, com pequena (ou nenhuma) quantidade de fase amorfa e fase líquida suficiente para atuar de forma significativa reduzindo a porosidade.

A existência de várias seqüências na Fig. 3, e de amostras (pontos no gráfico) que não se enquadraram em nenhuma das seqüências, traduz as peculiaridades composicionais e de queima de cada amostra, e ilustra bem a alternância do domínio de um dado parâmetro sobre os outros no que se refere ao efeito que provocam no comportamento de EPU dos materiais.

\section{EPU e Estimativa de Fase Vitrea}

Com base nos valores de quantidade estimada de fase vítrea e de EPU "potencial" (Tabela II), foi construída a Fig. 4 (a análise utilizando os teores de fase vítrea estimados exclusivamente a partir da quantidade de $\mathrm{K}_{2} \mathrm{O}$ apresentou, tal como esperado, maior dispersão nos resultados em virtude do elevado teor de $\mathrm{Na}_{2} \mathrm{O}$ existente em algumas amostras).

Na Fig. 4 observa-se de novo a existência de dependências distintas entre a EPU e a quantidade estimada de fase vítrea. Parte das amostras apresentou uma relação crescente entre a EPU e a quantidade de fase vítrea (seqüências 1 e 2), enquanto uma outra parcela apresentou uma relação decrescente entre a EPU e a quantidade de material vítreo (seqüências 3 e 4).

Tal como no caso da Fig. 3, pode-se explicar o comportamento ilustrado pelas curvas presentes na Fig. 4 como a combinação dos mesmos dois efeitos, a porosidade, que depende fortemente da quantidade de fase líquida desenvolvida durante a queima, e a composição mineralógica. Não surpreende, portanto, a semelhança entre as Figs. 3 e 4.

A Fig. 4 sugere que, para teores de fase vítrea abaixo de $25 \%$, existe uma predominância do efeito de "composição mineralógica" em relação à "redução da porosidade", sobre a EPU (seqüência 1). O efeito de redução da porosidade tornase mais significativo quando se atingem teores de fase vítrea entre 25 e $35 \%$. Nessa faixa de teores parece não haver uma definição nítida de qual efeito é mais significativo na determinação da EPU (seqüências 2 e 4). Para teores superiores a 35\% observa-se uma "predominância" do efeito de redução de porosidade (devida ao aumento de fase vítrea) sobre a EPU (seqüência 3).

As Figs. 3 e 4 mostram a influência de dois efeitos sobre a EPU dos corpos cerâmicos, um mineralógico e um estrutural, e evidenciam a possibilidade de controle da EPU do corpo pelo adequado controle desses dois efeitos. 

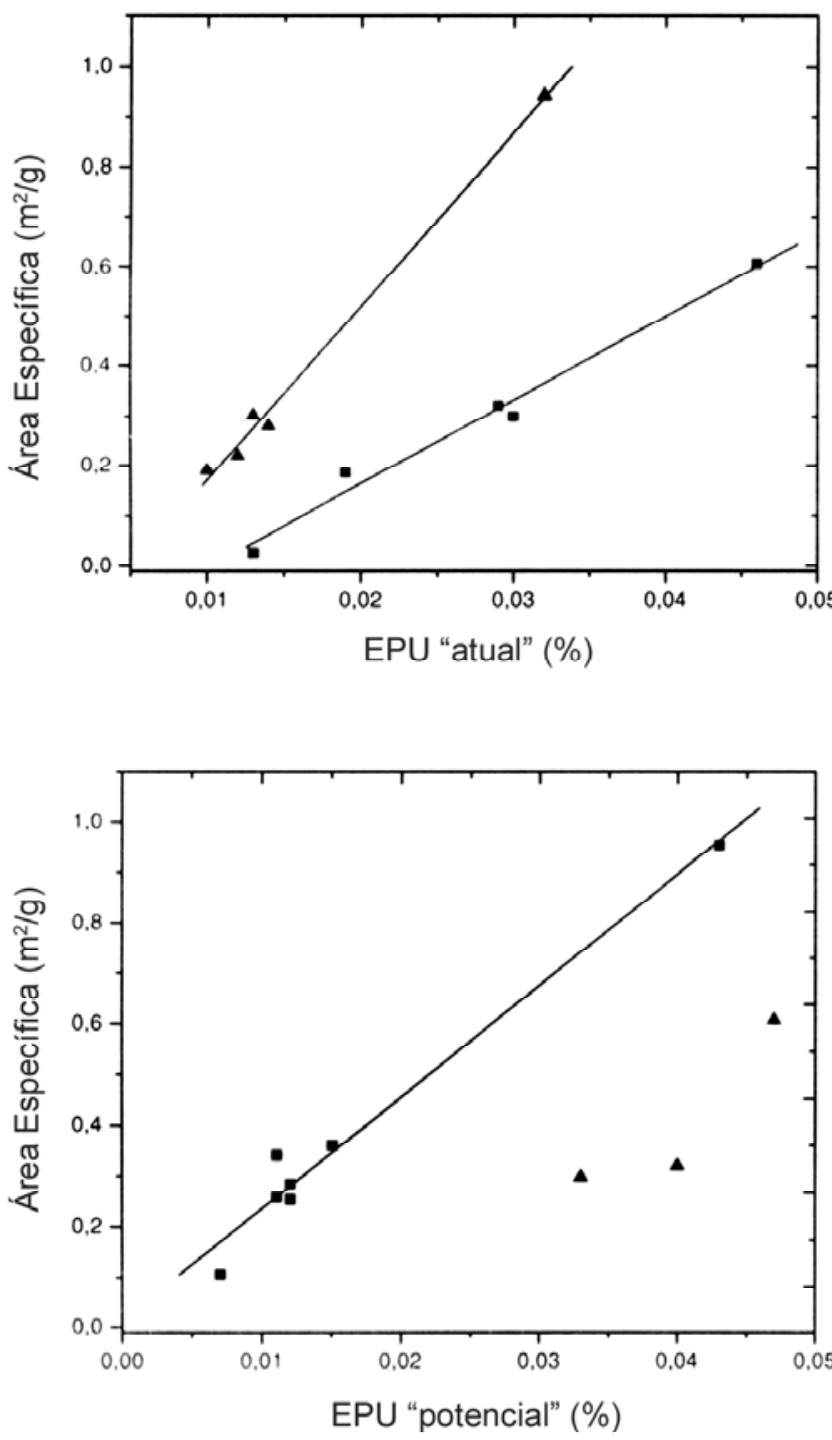

Figura 5: Área superficial específica versus EPU.

[Figure 5: Specific surface area versus moisture expansion.]

\section{EPU e Área Especifica}

A Tabela II apresenta os valores de área superficial específica obtidos através de adsorção de nitrogênio. Observa-se que os valores variaram de 0,1902 a $0,9419 \mathrm{~m}^{2} / \mathrm{g}$, com predominância dos resultados entre 0,26 e $0,32 \mathrm{~m}^{2} / \mathrm{g}$. Com base na Tabela II observa-se que não há uma relação direta entre área específica e o teor de fase vítrea, o que evidencia que a fase vítrea presente em algumas amostras não atua necessariamente reduzindo a porosidade do corpo cerâmico, tal como comentado anteriormente.

Com base na Tabela II foi construída a Fig. 5, que sugere uma relação proporcional entre a EPU e a área específica das amostras, tanto no que se refere a EPU "atual" como à "potencial". Os resultados de área específica e EPU "potencial" apresentam uma maior dispersão do que os relativos a EPU "atual", o que pode estar relacionado com uma possível contribuição para a EPU de adsorção química (irreversível) da água ocorrida durante o ensaio de fervura (a área específica foi determinada para amostras antes de fervura).

O comportamento mostrado na Fig. 5 está de acordo com a discussão anterior, já que materiais com elevada quantidade de fase vítrea apresentam pequena área específica e baixa EPU, enquanto que materiais com maior quantidade de material amorfo apresentam maior área específica e elevada EPU.

\section{CONCLUSÕES}

Este trabalho teve por objetivo relacionar a expansão por umidade de pisos cerâmicos comerciais de processamento desconhecido com a absorção de água, a composição química e a quantidade estimada de fase vítrea, calculada utilizandose o diagrama de equilíbrio de fases do sistema $\mathrm{SiO}_{2} \cdot \mathrm{Al}_{2} \mathrm{O}_{3} \cdot \mathrm{K}_{2} \mathrm{O}$ e a regra da alavanca. Deste estudo resultaram as seguintes conclusões:

a) apenas uma das amostras estudadas apresentou valor de expansão por umidade após fervura, superior ao valor limite indicado pela norma NBR $18818(0,06 \%)$, estando os valores de expansão por umidade situados entre 0,010 e $0,040 \%$ seja na expansão por umidade após fervura, seja na "atual";

b) as amostras apresentaram uma tendência de decréscimo da absorção de água com o aumento no teor estimado de fase vítrea;

c) parte das amostras apresentou uma dependência direta entre a expansão por umidade e a absorção de água enquanto outras apresentaram uma dependência inversa; parte das amostras apresentaram uma dependência direta entre expansão por umidade e teor estimado de fase vítrea enquanto outras apresentaram uma dependência inversa; estes resultados mostram a influência de dois efeitos sobre a expansão por umidade dos corpos cerâmicos, um mineralógico e um estrutural, e evidenciam a possibilidade de controle da expansão por umidade do corpo pelo adequado controle desses dois efeitos.

d) as amostras apresentaram uma relação diretamente proporcional entre expansão por umidade e área específica.

\section{REFERÊNCIAS}

[1] M. Y. L. Chew, Construction and Building Materials 13 (1999) 293.

[2] L. C. Chiari, C. J. Oliveira, C. Monteiro, N. V. Forjaz, E. Biscaro, A. O. Boschi, Cerâmica Industrial 1, 1 (1996) 6.

[3] A. M. Segadães, M. A. Carvalho, H. C. Ferreira (submetido para publicação)

[4] W. F. Cole, J. Aust. Ceram. Soc. 22, 1 (1986) 45.

[5] J. W. Mcburney, Proc. Am. Soc. Test. Mater. 54 (1954) 1219.

[6] A. N. Smith, Trans. Brit. Ceram. Soc. 54 (1955) 300.

[7] A. A. Milne, Trans. Brit. Ceram. Soc. 57 (1958) 148.

[8] J. E. Young, W. E. J. Brownell, J. Am. Ceram. Soc. 42, 12 (1959) 571.

[9] B. E. Yekta, P. Alizadeh, Am. Ceram. Soc. Bull. 75, 5 (1996) 84. 
[10] J. A. Slyh, Am. Ceram. Soc. Bull. 63, 12 (1984) 1495. [11] F. Vaughan, A. Dinsdale, Nature 183, 4661 (1959) 600. [12] M. Inzigneri, E. Fusarini, Trans. VII Internacional Ceramic Congress (1960) 53.

[13] H. G. Schurecht, G. R. Pole, J. Am. Ceram. Soc. 12, 9 (1929) 596.

[14] H. H. Holscher, J. Am. Ceram. Soc. 14, 3 (1931) 207.

[15] W. F. Cole, J. Am. Ceram. Soc. 45, 9 (1962) 428.
[16] P. S. Boucher, J. Aust. Ceram. Soc. 23, 1 (1987) 27.

[17] F. Vaughan, A. Dinsdale, Trans. Brit. Ceram. Soc. 61 (1962) 1.

[18] R. R. Menezes, "Estudo da expansão por umidade e de características cerâmicas correlatas de placas cerâmicas para revestimento", Dissertação de Mestrado, Coordenação de PósGraduação em Engenharia Química, UFPB (2001).

(Rec. 27/12/02, Rev. 19/03/03, Ac. 21/03/03) 